\title{
O CONCEITO DE MEIO TÉCNICO-CIENTÍFICO-INFORMACIONAL EM MILTON SANTOS E A NÃO-VISÃO DA LUTA DE CLASSES
}

\author{
THE CONCEPT OF TECCHICAL-SCIENTIFIC-INFORMATIONAL \\ ENVIRONMENT BY MILTON SANTOS AND THE NON-VISION OF \\ CLASS STRUGGLE
}

\section{EL CONCEPTO DE MEDIO TECNICO-CIENTIFICO- INFORMACIONALE EN MILTON SANTOS Y LA NO-VISION DE LA LUCHA DE CLASSES}

\author{
Lucas Maia \\ Graduado e Mestre em Geografia pelo Instituto de Estudos Socioambientais da UFG \\ Professor do Instituto Federal de Goiás - Campus Anápolis \\ Av. Pedro Ludovico, s/n, Reny Cury. CEP: 75131-500. Anápolis - GO \\ E-mail: maiaslucas@yahoo.com.br
}

\section{Resumo}

Este texto visa discutir o conceito de meio técnico-científico-informacional em Milton Santos. A tese que defendemos é que no processo de construção do conceito, Milton Santos considerou indiretamente ou só considerou de modo secundário a luta de classes. Isto tem implicações metodológicas e políticas de certa importância. Após discutir como o autor elaborou o conceito em pelo menos duas décadas considerando a questão, apresentamos em seguida nossa apreciação crítica, demonstrando como ele considerou de modo secundário as lutas de classes na constituição do meio técnico-científicoinformacional. Para a realização deste estudo, analisamos fundamentalmente a obra $A$ Natureza do Espaço, texto no qual ele desenvolve de modo mais acabado o conceito de meio técnico-científico. Consideramos também, de modo mais secundário, um conjunto de outros textos nos quais ele aborda direta ou indiretamente a questão. Nossa intenção não foi desconsiderar a contribuição deste autor para as pesquisas em Geografia. Pelo contrário, queremos, a partir do que ele nos legou, aprofundar as discussões relativas a este conceito, que muito tem ainda de elementos explicativos da realidade.

Palavras-chave: meio técnico-científico-informacional; Milton Santos; luta de classes.

\begin{abstract}
This texts aims at discussing the concept of technical-scientific-informational environment by Milton Santos. The thesis defended here is that, in the process of constructing the concept, Milton Santos did not take class struggle into consideration, or did it in a secondary plan. This conclusion has methodological and political implications of reasonable importance. After discussing how the author elaborated the concept through at least two decades, our critical appreciation of the subject is presented by demonstrating how the author disregarded class struggle in constituting technical-
\end{abstract}

Ateliê Geográfico Goiânia-GO v. 6,n. $4 \quad$ Dez/2012 $\quad$ p.175-196 Página 175


scientific-informational environment. This studied was essentially held through the analysis of $A$ Natureza do Espaço, text in which the concept of technical-scientificinformational environment is developed in a better finalized way. A set of other texts were also taken into account in a secondary way, texts in which the author addresses the issue directly or indirectly. The intention of this study was not to undervalue this author's contributions to the researches in Geography. On the contrary, we aim at, from his legacy, deepening the discussions regarding this concept, which has plenty of explanatory elements of reality.

Keywords: Technical-scientific-informational environment; Milton Santos; class struggle.

\section{Resumen}

Este texto tiene como objetivo discutir el concepto de medio técnico-científicoinformacional de Milton Santos. La tesis aquí es que, en el proceso de construcción del concepto, Milton Santos no tuvo en cuenta la lucha de clases, o lo hizo en un plan secundario. Esta conclusión tiene implicaciones metodológicas y políticas de cierta importancia. Después de explicar cómo el autor elaboró el conceptoen por lo menos dos décadas, nuestra apreciación crítica se presenta, demostrando cómo el autor considera la lucha de clases en la constitución de el medio técnico-científicoinformacional. Este estudio se llevó a cabo a través, en esencia, del análisis de $L a$ Naturaleza del Sspacio, texto en lo que el concepto de medio técnico-científicoinformacional se desarrolla de una manera mejorterminada. Otro conjunto de textos también se consideró, de manera secundaria, textos en los que el autor aborda el tema de forma directa o indirecta. La intención de este estudio no fue a subestimar las contribuciones de este autor a las investigacións en Geografía.Por el contrario, nuestro objetivo es, a partir de su legado, profundizar los debates sobre este concepto, que tiene muchos elementos explicativos de la realidad.

Palabras clave: Medio técnico-científico-informacional; Milton Santos; lucha de clases

\section{Introdução}

O conceito de meio técnico científico-informacional é um dos mais conhecidos na geografia, pelo menos a brasileira. Trata-se de um conceito que o geógrafo Milton Santos desenvolveu e aprofundou durante pelo menos duas décadas. Várias de suas obras apresentam este conceito. Em algumas delas, ele aparece mais como uma noção, como um conceito em potência de se desenvolver, em outras, ele aparece como um conceito plenamente elaborado. Na obra A Natureza do Espaço, este conceito é elaborado teoricamente de modo bastante claro, a analisaremos em

Ateliê Geográfico Goiânia-GO $\quad$ v. 6, n. $4 \quad$ Dez/2012 $\quad$ p.175-196 Página 176


pormenores mais adiante. No livro publicado em co-autoria com Maria Laura Silveira, intitulado: O Brasil: território e Sociedade no Início do Século XXI, este conceito é utilizado para fazer uma leitura da formação, desenvolvimento e estado atual do território brasileiro.

Objetivamos, com este artigo, analisar a maneira segundo a qual Milton Santos desenvolveu este conceito, identificando seus pressupostos teóricometodológicos. Para tanto, analisaremos como o conceito aparece no conjunto de sua obra, mas principalmente no livro A Natureza do Espaço.

Por último, demonstraremos como na perspectiva miltoniana o conceito de meio técnico-científico-informacional apresenta limitações. A tese que buscaremos desenvolver é de que Milton Santos só considera de modo indireto a luta de classes na constituição do meio técnico-científico-informacional e tudo o que deriva daí, principalmente o movimento do capital e seu processo de reprodução ampliada, bem como os movimentos de contestação ao capital: movimento operário, demais movimento sociais etc. Ao proceder de tal maneira, as possibilidades explicativas do conceito ficam aquém da realidade, não conseguindo, deste modo, explicá-la satisfatoriamente, conformando-se desta maneira não como um conceito, mas sim como um construto ${ }^{1}$.

\section{Meio técnico-científico-informacional: a construção do conceito}

O meio técnico científico-informacional, tal como elaborado por Milton Santos, é um construto que necessita de aprofundamento e considerações de caráter ontológico para transformar-se em conceito. Ele aparece, como preocupação teórica do autor, em várias obras. Uma das primeiras vezes em que ele utiliza a expressão meio

\footnotetext{
${ }^{1}$ Para uma discussão sobre isto Cf. Viana (2007). Ele distingue entre conceito e construto, sendo o primeiro um conceito verdadeiro e o segundo falso conceito. Distingue também entre conceito singular e universal. $\mathrm{O}$ primeiro remete a uma realidade específica e determinada geográfica e historicamente. $\mathrm{O}$ segundo permite abarcar todas as formas de organização social. Apresenta a existência de conceitos antecipadores e conceitos expressivos. Estes expressam uma realidade existente ou que existiu concretamente. Aquele expressa uma realidade que existe como potência, como projeto. Distingue também conceito e construto de categoria. Esta não tem referente no real. É uma ferramenta intelectual, um recurso heurístico. Separa também analiticamente conceito, construto e categoria de noção. Esta é um conceito ou um construto em potência de se formalizar, em potência de ser desenvolvido. Desta forma, de acordo com esta "caracterologia", temos que o meio técnico-científico-informacional é um construto expressivo de uma realidade específica. Procuraremos aqui torná-lo um conceito adequado para se compreender a realidade contemporânea.
}

$\begin{array}{llllll}\text { Ateliê Geográfico Goiânia-GO } & \text { v. 6, n. } 4 & \text { Dez/2012 } & \text { p.175-196 } & \text { Página } 177\end{array}$


técnico-científico é quando da publicação de seu livro Espaço \& Método. A primeira edição desta obra se dá em 1985. Por esta época, ainda não se tinha, de modo difundido e presente, o discurso da globalização. Quando, na década de 1990 em diante, o discurso da globalização começa a penetrar nas universidades brasileiras, Milton Santos começa a incorporar no construto meio técnico-científico a palavra informacional. Segundo ele, este meio técnico-científico-informacional é a cara espacial da globalização e a informação e os sistemas comunicacionais adquirem importância capital em sua leitura.

Sumariamente, propõe cinco períodos para o desenvolvimento da sociedade capitalista, sendo que cada um destes períodos, "sistemas temporais", coincidem com a sucessão dos "sistemas de modernização".

Afirma:

1) Período do comércio em grande escala (a partir dos fins do século $X V$ até mais ou menos 1620); 2) O período manufatureiro (1620 - 1750); 3) O período da revolução industrial $(1750$ - 1870); 4) O período industrial (1870 - 1945); 5) O período tecnológico (Santos, 1997a, p. 23) (grifos meus)

Este quinto período, do fim da segunda guerra mundial para cá, corresponde à constituição do meio técnico-científico. Seria a constituição de um espaço completamente diferente dos períodos anteriores. A cada um destes períodos, ocorre o que ele denomina de "sistemas de modernização". Já está bastante claro que para ele as sucessões dos períodos são sucessões de sistemas técnicos. Esta é a peculiaridade da leitura espacial, visto que só pode ser feita desta forma. Cada período corresponde uma determinada família de técnicas. À medida que vão se incorporando novos sistemas de modernização, ou seja, à medida que as técnicas vão se modificando, entramos num novo período do desenvolvimento histórico da sociedade capitalista.

Este novo período distingue-se dos demais, dentre vários outros motivos, pelo fato de que:

A tecnologia da comunicação permite inovações que aparecem, não apenas juntas e associadas, mas também para serem propagadas em conjunto. Isto é peculiar à natureza do sistema, em oposição ao que sucedia anteriormente, quando a propagação de diferentes variáveis não era necessariamente acelerada (Santos, 1997a, p. 27) (grifos meus). 
A modificação acelerada, a velocidade, a incorporação sempre crescente de novos capitais fixos ao território (estradas, ferrovias, portos, aeroportos, instalações fabris etc.), a chegada e dispersão das técnicas de comunicação e informação etc. vão dar a este período uma forma nova que o diferencia dos demais. Isto provoca o que ele denomina de instantaneidade dos momentos e dos lugares, universalidade e unicidade das técnicas etc.

Afirma:

Esta instantaneidade e universalidade na propagação de certas modernizações desmantela a organização do espaço anterior. Constitui, sobretudo, um fator de dispersão que se opõe de uma forma muito clara aos fatores de concentração conhecidos nos períodos anteriores (Santos, 1997a, p. 29)

Assim, a passagem do meio técnico (que perdurou até o quarto período) para o técnico-científico se dá quando há: “(...) o desenvolvimento da ciência das técnicas, isto é, da tecnologia, e, desse modo, com a possibilidade de aplicar a ciência ao processo produtivo" (Santos, 1997a, p. 37). Para Milton Santos, a incorporação e a interdependência entre desenvolvimento técnico e ciência conformam ou criam as possibilidades de construção de um novo espaço, o meio técnico-científico.

No livro Técnica, Espaço, Tempo: globalização e meio técnico-científico informacional, publicado pela primeira vez em 1994, Milton Santos dá uns passos adiante na elaboração de seu conceito. Destaco o subtítulo do livro, no qual meio técnico-científico informacional aparece associado à idéia de globalização. Assim, o conjunto de construtos ligados ao discurso da globalização vão povoar o sistema construtual de Milton Santos quando aborda o meio técnico-científico informacional.

Defende que estamos transitando de uma sociedade industrial para uma sociedade informacional, pois, para ele, em que pese esta transição ainda não tenha se completado, é, contudo, uma tendência que se afirma a cada dia. Esta nova fase carece ainda de uma interpretação geográfica mais consistente e ele julga estar criando os conceitos adequados para tanto. Nesta tarefa homérica de criar uma "uma consciência de uma época nova”, Santos (1998) aponta os seguintes pontos: 
- A relação entre ciência e técnica é no período atual uma relação de interdependência. Materializa-se no espaço constituindo o meio técnico científico-informacional.

- O desenvolvimento técnico permite hoje a simultaneidade dos lugares e dos tempos.

- As técnicas hoje compõem um único sistema. Em que pese haja diferenças de forma e intensidade de acordo com os países, todo o sistema técnico atual é interdependente. Isto ele chama de unicidade técnica.

- Tal unicidade é garantida pela mais-valia tornada mundial. (embora a maneira como expresse a questão seja conceitualmente confusa, é, contudo, correta. Seria melhor falar em expansão das relações capitalistas a escala mundial, a mais-valia é a essência do modo de produção capitalista, mas a sua existência pressupõe um conjunto de relações sociais que é necessário levar em consideração).

- O papel dos fluxos de informação na constituição do espaço, o papel do sistema de créditos (bancos) - creditização do espaço.

Todos estes itens elencados permitem uma leitura mais próxima, de acordo com Milton Santos, do período atual e principalmente de sua manifestação geográfica, o meio técnico-científico-informacional. Aborda outros elementos para caracterizar este período, tal como modificações na relação campo-cidade, rede urbana, espaço intraurbano etc. Até este momento de sua elaboração, o meio técnico científicoinformacional ainda não se apresenta como um conceito lapidado, trata-se ainda de uma noção em vias de se tornar conceito.

É, contudo, no livro A Natureza do Espaço: Técnica e Tempo, Razão e Emoção, que esta noção é desenvolvida em sua forma mais acabada. Publicado em 1996, este livro é uma proposta teórico-metodológica de análise geográfica. Tem no meio técnico-científico-informacional seu principal nexo estruturante. Nesta obra, há a apresentação de como o autor concebe que os estudos geográficos devem encarar a realidade contemporânea.

Uma análise detalhada desta obra demandaria várias páginas, espaço que não dispomos nos limites deste texto. Objetivamos aqui tão-somente expor em linhas gerais o que ele concebe por meio técnico-científico-informacional e quais as implicações político-sociais de suas observações. Nossa análise não abarcará, portanto, a totalidade 
do livro. Destacaremos os elementos que nos são necessários para compreender a matéria que agora colocamos em discussão.

Ao debater o que denomina de "ontologia do espaço: noções fundadoras", o primeiro elemento que ele destaca e que irá permear todo o conjunto da obra é a discussão sobre técnica, espaço e tempo. De maneira bem sumária, ele define técnica como sendo: “(...) um conjunto de meios instrumentais e sociais, com os quais o homem realiza sua vida, produz, e ao mesmo tempo, cria espaço" (Santos, 1997b, p. 25). Esta definição sumária não consegue, contudo, expressar bem sua concepção com relação à questão. Este é simplesmente o ponto de partida. A partir desta concepção inicial, ele deriva toda sua análise do espaço e como este se transforma ao longo do tempo, configurando o espaço geográfico, até culminar, na época atual, no meio técnicocientífico-informacional. Para ele: "Só o fenômeno técnico na sua total abrangência permite alcançar a noção de espaço geográfico" (Santos, 1997b, p. 31). Ou seja, o espaço geográfico é antes de tudo uma condição e um fenômeno técnico ele próprio.

Assim:

Na realidade, toda técnica é história embutida. Através dos objetos, a técnica é história no momento da sua criação e no de sua instalação e revela o encontro, em cada lugar, das condições históricas (econômicas, socioculturais, políticas, geográficas), que permitiram a chegada desses objetos e presidiram à sua operação. A técnica é tempo congelado e revela uma história (Santos, 1997b, p. 40)

Como os sistemas técnicos se materializam no espaço, constituindo-o, eles permitem compreender a história dos lugares. Esta idéia tem uma implicação metodológica muito profunda para os estudos geográficos, visto que permite datar, situar no tempo e no espaço a história dos lugares. Milton Santos denomina isto de "as técnicas e a empiricização do tempo". As técnicas não aparecem isoladas. Elas se mostram sempre como um conjunto de técnicas que materializam geograficamente uma determinada sociedade num dado momento histórico específico.

Com as técnicas “(...) empiricizamos o tempo, tornando-o material e desse modo o assimilamos ao espaço, que não existe sem a materialidade. A técnica entra aqui como um traço de união, historicamente e epistemologicamente" (Santos, 1997b, p. 44). Com esta assertiva, Milton Santos busca apresentar o caráter metodológico da consideração das técnicas nos estudos geográficos. É com base nestas considerações que

Ateliê Geográfico Goiânia-GO v. 6,n. $4 \quad$ Dez/2012 p.175-196 Página 181


o autor apresenta sua definição de espaço geográfico: "O espaço é formado por um conjunto indissociável, solidário e também contraditório, de sistemas de objetos e sistemas de ações, não considerados isoladamente, mas como o quadro único no qual a história se dá" (Santos, 1997b, p. 51). As ações são sempre intencionais e os objetos estão sempre inseridos dentro de um quadro de ações. Ações e objetos conformam um quadro social dado e configura uma forma espacial específica, geográfica e historicamente determinada, cuja manifestação empírica imediata se apresenta na paisagem.

No livro que agora analisamos, A Natureza do Espaço, o autor apresenta a "evolução" das formas espaçais. As sociedades, em seu devir histórico, caminham do "meio natural", passando pelo "meio técnico", até chegar na sua formação atual, o "meio técnico-científico-informacional". A isto, ele denomina "os períodos técnicos". A cada época histórica há, portanto, simultaneamente uma época geográfica, visto que a história está embutida nos sistemas técnicos e estes se realizam em grande medida como “objetos geográficos".

Citando Fu-chen Lo, Milton Santos propõe etapas sucessivas das técnicas para a compreensão do desenvolvimento das sociedades. Descreve como a partir do século 18 se deu a evolução de algumas técnicas, acreditando apresentar com esta proposição as etapas pelas quais passou a sociedade moderna. Assim, passamos por cinco "paradigmas tecnoeconômicos": a) primeira mecanização - de 1770 a 1840; b) máquina a vapor e estrada de ferro - 1830 a 1890; c) eletricidade e engenharia pesada 1880 a 1940; d) produção fordista de massa - 1930 a 1990; e) informação e comunicação - 1980... (Santos, 1997b, p.139). Por último, observa que este autor, Fuchen Lo, em sua proposição “(...) deixa espaço vazio para as novas inovações relativas à informação e à comunicação, onde parecem residir os principais elementos do mundo novo a cuja formação estamos assistindo" (Santos, 1997b, p. 140). Ou seja, para Santos, Fu-chen Lo identificou o novo no que se refere aos processos técnicos, mas não conseguiu avançar em sua descoberta. É justamente aí que Milton Santos buscará incidir suas contribuições.

A passagem de cada um destes períodos para o seguinte se dá a partir da inserção de novas técnicas no sistema de técnicas já instalado no território. O último período é caracterizado em grande medida pela generalização e aprofundamento do

Ateliê Geográfico Goiânia-GO v. 6,n. 4 Dez/2012 p.175-196 Página 182


papel da informação e da comunicação nos sistemas produtivos. Daí Milton Santos caracterizar o período técnico atual como sendo o da constituição de um "meio técnicocientífico-informacional".

O meio técnico-científico-informacional inicia-se na década de 1970; é caracterizado pela aplicação da ciência à técnica, por isto meio técnico científico; mas este meio, estas técnicas são impregnadas de informação e transmitem, acumulam informação, por isto meio técnico-científico-informacional.

Assim,

Os espaços assim requalificados atendem sobretudo aos interesses dos atores hegemônicos da economia, da cultua e da política e são incorporados plenamente às novas correntes mundiais. $\mathrm{O}$ meio técnico-científicoinformacional é a cara geográfica da globalização (Santos, 1997b, p. 191).

Acredito ter sido bastante claro quanto à exposição do processo de construção do construto meio técnico-científico-informacional. Podemos agora passar às apreciações críticas quanto aos limites que Milton Santos não conseguiu superar em sua elaboração conceitual. Vejamos quais são eles.

\section{O ponto-cego no conceito de meio técnico-científico-informacional: a luta de classes}

Desenvolverei a argumentação seguindo o seguinte esquema. Primeiramente, demonstrarei como, em Milton Santos, há uma concepção contraditória quanto à da determinação da tecnologia pelas relações sociais; isto o conduz a considerar que o desenvolvimento da sociedade se dá pela transformação dos sistemas técnicos, ou seja, ele autonomiza em certa medida o desenvolvimento técnico. Por isto sua concepção acerca do desenvolvimento histórico da humanidade ou os períodos ou etapas pelas quais já passou, mas sobretudo a sociedade capitalista, apresenta um esquema descritivo; isto se dá, de acordo com a tese que buscaremos defender aqui, pelo fato de ele considerar de modo secundário a luta de classes como um elemento estruturante de sua análise.

Sua postura com relação à determinação da tecnologia pelo conjunto das relações sociais é ambígua. Em linhas gerais, no conjunto de suas afirmações, ele

Ateliê Geográfico Goiânia-GO v. 6,n. 4 Dez/2012 p.175-196 Página 183


apresenta uma leitura segundo a qual as "ações", a política, as "intencionalidades" etc. são o elemento fundamental para o desenvolvimento técnico. Isto parece uma obviedade, mas há momentos em suas afirmações nos quais parece-se perder de vista esta assertiva. Assim, ao mesmo tempo em que concebe o processo técnico, ou seja, a constituição dos objetos como resultado e condição das ações na constituição do espaço, em outros, aparecem concepções que dão certa autonomia ao desenvolvimento técnico.

Isto pode ser observado, por exemplo, quando afirma:

A tecnologia constitui não apenas uma esfera da realidade, mas uma ordem da realidade, possuidora de sua própria racionalidade (...). As inovações técnicas se encontram com a história portando suas próprias regras, às quais as demais escolhas devem curvar-se (Santos, 1997b, p. 238).

A técnica possui sua própria racionalidade? Isto é uma excrescência. Ela é imbuída de racionalidade que as relações sociais lhe conferem. Ela não tem racionalidade própria, mas tão somente expressa uma racionalidade que é a dominante. Todo o meio técnico-científico constituído possuiria, nesta assertiva, uma certa autonomia que de fato não possui. As inovações técnicas se encontram com a história? Claro que não. As inovações técnicas são a história materializada geograficamente. Isto nós já vimos que ele próprio afirmou em outro momento de sua obra. Assim, com relação a este aspecto, Milton Santos apresenta uma certa ambigüidade que é necessário destacar. Ao mesmo tempo que considera o desenvolvimento técnico como sendo uma condição e um produto do desenvolvimento histórico, melhor dizendo, como sendo a própria "história empiricizada" nos objetos, afirma em contrapartida que as técnicas são possuidoras de uma racionalidade própria, que possuem suas próprias regras etc.

A gravidade desta afirmação é facilmente perceptível. Como imaginar um meio técnico desenvolvendo-se por si mesmo, de acordo com sua própria lógica e racionalidade? Como imaginar as ferrovias, os portos, aeroportos, instalações fabris e de logística, as estradas e os prédios inteligentes, o ciberespaço e as metrópoles, os campos infestados com a bioengenharia, com os insumos e maquinaria agrícola etc. funcionando de acordo com sua própria lógica, com sua própria "racionalidade", com suas próprias regras? Vê-se o absurdo lógico ao qual esta idéia pode chegar.

Não há, definitivamente, nenhuma regra intrínseca aos processos técnicos. Estes, pelo contrário, são ampla e totalmente determinados pelo conjunto das relações 
sociais. E é por isto que podemos datar as técnicas, é por isto que podemos historicizar as técnicas. Isto Milton Santos afirma em vários lugares, mas não pode, no conjunto de suas afirmações, livrar-se deste fantasma do determinismo tecnológico. Isto nos conduz a pensar que para o autor, esta questão não está plenamente resolvida. Em que pese faça considerações e considerações com relação à historicidade das técnicas, permite, no contexto de sua análise que uma excrescência como esta apareça. Ou seja, deriva daí que o pensamento de Milton Santos apresenta uma contradição interna de certa gravidade. Ele termina sua argumentação sem resolvê-la.

Isto pode ser observado ainda, quando logo em seguida afirma, comentando Langdon Winer: "É como, diz ele, se as inovações técnicas se comportassem como se fossem leis. A cada período técnico corresponde uma mudança geral nas relações sociais" (Santos, 1997b, p. 238). Ou seja, as técnicas determinando as relações sociais e as mudanças sociais. Uma completa inversão da realidade. Toma a técnica como algo absoluto, uma "ordem própria" da sociedade, com leis próprias etc. As técnicas não tem leis próprias, não são uma ordem própria da realidade, não são um dado em si mesmas. As técnicas são sempre uma derivação do conjunto das relações sociais e principalmente das relações de produção.

Isto deriva: a) do fato dele descrever a história das técnicas sem inseri-las numa teoria geral da transformação das relações sociais, falha que apresenta como subjacente a não-visão da luta de classes; b) também, no que se refere à história do capitalismo, ele não consegue derivar uma história das técnicas e do meio técnico como sendo esta o resultado de um conjunto de processos sociais, que culminam nos sucessivos regimes de acumulação ${ }^{2}$; e c) uma história das técnicas no capitalismo é uma história dos regimes de acumulação.

Esta reflexão nos conduz ao segundo ponto que quero destacar, ou seja, não existe na leitura de Milton Santos uma teoria do desenvolvimento capitalista, mas tãosomente uma visão etapista-descritiva da sucessão histórica do capitalismo. Isto deriva em grande medida da supervalorização dada por ele ao fenômeno técnico. Este é simultaneamente seu ponto mais forte e paradoxalmente seu calcanhar de Aquiles. Seu ponto forte justamente por perceber a importância que a constituição do meio técnico desempenha na sociedade contemporânea. Perceber este meio técnico é

\footnotetext{
${ }^{2}$ Para uma discussão sobre a teoria dos regimes de acumulação, cf. Viana $(2003 ; 2009)$.
} 
simultaneamente a oportunidade de melhor o compreender e ao compreendê-lo explicase mais satisfatoriamente a realidade contemporânea. É seu calcanhar de Aquiles por que no processo de análise, este meio técnico é supervalorizado ${ }^{3}$, autonomizado. É isto que lhe permite, por exemplo, encontrar leis próprias no desenvolvimento técnico. Para além deste aspecto, um outro muito mais grave diz respeito à periodização que ele faz da sociedade capitalista. Devido ao seu fetichismo técnico, vê na sucessão de períodos do capitalismo, a sucessão de etapas técnicas ou de sistemas técnicos, tal como já analisamos no tópico anterior.

O processo, contudo, é um pouco mais amplo. Não se trata somente da sucessão de sistemas técnicos. Para tanto, teríamos de entrar na teoria dos regimes de acumulação de capital tal como desenvolvida por Viana $(2003 ; 2009)$. A teoria dos regimes de acumulação foi desenvolvida por Viana a partir das contribuições da escola francesa de regulação, das contribuições de David Harvey, Benakouche etc. A partir de uma leitura crítica de todos estes autores, Viana, nas referidas obras, apresenta o que entende por regime de acumulação de capital.

O desenvolvimento capitalista é marcado pela sucessiva mudança no regime de acumulação. Um regime de acumulação é constituído por uma determinada forma assumida pelo processo de valorização, uma determinada forma de organização estatal e um modo específico de relação entre os países capitalistas, ou seja, de relações capitalistas internacionais (Viana, 2003, p. 83)

A combinação destes elementos constituem etapas ou períodos da sociedade capitalista. Não temos espaço aqui para fazer uma análise muito extensa de como ele discute cada um dos regimes de acumulação. Nos restringiremos aqui a apresentar cada um deles. O primeiro regime, após findada a acumulação primitiva de capital, é denominado por Viana $(2003 ; 2009)$ de regime de acumulação extensivo. Estende-se do final do século 18 até as últimas décadas do século 19. Caracteriza-se pelo predomínio da extração de mais valia absoluta, pelo estado liberal e por relações internacionais fundadas no neo-colonialismo.

O segundo, após a crise deste regime que se deu nas últimas décadas do século 19, é denominado pelo autor de regime de acumulação intensivo. Estende-se do

\footnotetext{
${ }^{3}$ Isto deriva, claro, da especialização acadêmica do autor, que valora de modo mais intenso seu quinhão do conhecimento.
} 
final do século 19 até a segunda guerra mundial. É caracterizado pela predominância da extração de mais valia absoluta, onde o taylorismo destaca-se como a "técnica" predominante de exploração da força de trabalho. O estado adequado a este tipo de produção foi o estado liberal-democrático, que reconhecia algumas organizações de trabalhadores, tal como os sindicatos e os partidos, mas integrando-os à lógica do capital. E as relações internacionais passam, neste momento, a serem pautadas pela exploração imperialista internacional.

A etapa que o sucede é denominada por Viana de regime de acumulação intensivo-extensivo. Estende-se da década de 1950 até final dos 1970 e início dos 1980. Do ponto de vista do processo de exploração do trabalho, ou seja, da valorização do capital, caracteriza-se pelo predomínio de extração de mais-valia relativa nos países de capitalismo central (imperialistas) e mais-valia absoluta nos países de capitalismo subordinado. O fordismo foi a "técnica" desenvolvida como forma de valorização do capital. É o período de extensão das teias da produção capitalista para várias partes do mundo, as conhecidas multinacionais são sua expressão empírica. Este sistema de exploração exigia, nos países imperialistas um estado adequado. Este foi edificado com os princípios keineisianos. Assim, o estado integracionista, de bem-estar-social etc. só foi possível nos países imperialistas mediante uma exploração internacional absurda. A extração de mais valia passa a ser agora internacional. Os países "pobres", agora afogados pela produção capitalista, exportam um quantum sempre crescente de maisvalia. Isto só foi possível mediante o estabelecimento do imperialismo oligopolista, ou seja, o imperialismo dominado e capitaneado não mais somente pelos estados, mas sobretudo pelas empresas capitalistas que tem agora capital produtivo instalado em várias partes do mundo.

A crise dos anos de 1970 testemunha o desmoronamento deste regime de acumulação e a criação das raízes de uma nova etapa da exploração capitalista, o regime de acumulação integral, etapa atual do capitalismo. Este estende-se do início da década de 1980 e permanece até os dias atuais. É caracterizado pelo aumento da extração de mais valor absoluto e relativo em escala internacional. Todos os países do mundo aumentam a exploração da força de trabalho. O toyotismo é a "técnica" adequada de valorização "flexível” do capital. Como ressalta Viana (2003), claro que a flexibilização se dá somente do ponto de vista do capital, já que do ponto de vista do trabalhador, 
trata-se de uma inflexibilidade gritante. A forma estatal adequada à exploração "flexível" da força de trabalho é o estado neoliberal. As relações internacionais são caracterizadas pelo aprofundamento do imperialismo oligopolista e pelo belicismo da economia. A isto Viana (2003) deu o nome de neo-imperialismo.

Da maneira como expusemos, de forma descritiva e sumária a sucessão dos regimes de acumulação, em nada difere das formas convencionais de se periodizar o desenvolvimento histórico, nem muito menos de como Milton Santos faz, descrevendo etapas técnicas, sistemas técnicos. É necessário ir além da descrição. Temos de alcançar a explicação. Como se dá a passagem de um para outro regime de acumulação? Quais são as forças sociais que provocam tal mudança? Quais as implicações, do ponto de vista geográfico, ou seja, da constituição do meio técnico, da sucessão destes regimes de acumulação?

Viana (2009) aponta uma explicação que a priori nos parece bastante satisfatória. Dois processos diferentes, mas interdependentes se interpenetram conformando as transformações pelas quais passam o modo de produção capitalista. Tal leitura vale única e exclusivamente para a análise da sociedade burguesa, não podendo, portanto, ser transposta para outros tipos de sociedade. Um é a "lei tendencial da queda da taxa de lucro" e o outro é a luta de classes ou a ascensão da resistência operária e das demais classes oprimidas da sociedade. A combinação destes processos gera crises sucessivas nos regimes de acumulação apontando inclusive as possibilidades de superação da própria acumulação capitalista.

Não disponho de espaço nos limites deste texto para expor em detalhes o que Marx (1988) definiu como tendência declinante da taxa de lucro. Em linhas gerais, ele apresenta, com esta concepção, as contradições internas da produção capitalista. A tendência do capital é aumentar cada vez mais sua composição orgânica. Isto implica que há uma diminuição relativa de capital variável em relação ao capital constante. $O$ resultado deste processo é a diminuição progressiva da taxa de lucro. Só quem gera valor novo é a força de trabalho. Se esta, no processo produtivo, diminui progressivamente, também, progressivamente diminui a quantidade de valor novo, portanto, de mais-valia incorporada nas mercadorias.

Deste modo, embora a cada ciclo de reprodução ampliada do capital, haja uma taxa de lucro extraída pelo capitalista do processo produtivo, esta taxa é, contudo, 
progressivamente menor. No momento em que esta diminuição prejudica a reprodução ampliada, instala-se um período de crise. O capital cria, em contrapartida, as contratendências: ação estatal, aumento da exploração da força de trabalho empregada, aumento de mercado consumidor, o que implica em aumento da produtividade, portanto aumento da exploração etc. Ou seja, o capital cria em seu próprio interior, dificuldades sempre crescentes de se reproduzir, mas isto não o conduz necessariamente à tão sonhada derrocada final do capitalismo. O capitalismo não acabará por si mesmo como produto de uma entropia inevitável.

É aí que entra o segundo elemento a ser considerado: a luta de classes, a ação contestadora dos explorados. Tal contestação ocorre no cotidiano da produção capitalista, tal como no roubo de mercadorias, na desatenção dentro do processo produtivo, no absenteísmo (ato de faltar ao trabalho sem motivo determinado) etc. Esta contestação cotidiana cede, em determinados momentos, espaço a uma contestação mais radical, onde a greve, a paralisação, a passeata etc. aparecem como recursos de contestação das classes exploradas. E em momentos revolucionários, cria-se a possibilidade de superação do capitalismo ${ }^{4}$. Ou seja, a luta de classes é um elemento que juntamente com a tendência declinante da taxa de lucro coloca em questão a normalidade da produção capitalista. Assim, a tendência declinante da taxa de lucro e a luta de classes como processos imanentes ao capitalismo o colocam periodicamente em crise. Uma crise de acumulação pode gerar, tendencialmente, a superação do próprio capitalismo. Ou seja, a cada crise de um regime de acumulação são colocadas as possibilidades de edificação de uma sociedade radicalmente diferente, fundada em novas bases sociais. Esta não será produto da "crise final" do capitalismo, mas sim da ação criadora das classes exploradas e principalmente do proletariado levando o capitalismo à sua fase final.

O regime de acumulação é, portanto, uma etapa do desenvolvimento capitalista. A essência do desenvolvimento capitalista é a extração de mais-valor. São desdobramentos da extração de mais-valor: acumulação de capital, que tem como fundamento a reprodução ampliada do capital, que gera a concentração e centralização de capitais, que por sua vez tem como necessidade a expansão mundial do capitalismo, ou seja, a exploração internacional, tudo isto "ao lado da ação estatal no sentido de

\footnotetext{
4 Para uma análise do processo de ascensão das lutas operárias, passando pelos estágios "espontâneo", "autônomo" e "autogestionário", cf. Jensen (2001).
} 
garantir todo este processo" (Viana, 2009, p. 31). A acumulação tem como consequiência a resistência operária, o que agrava a dificuldade de reprodução do capital. A produção de mais-valor gera paradoxalmente a tendência declinante da taxa de lucro. Estes dois processos são reforçados simultaneamente um pelo outro.

Assim, retornando à discussão anterior, ou seja, à periodização descritiva de Milton Santos, ao proceder assim, ele não compreende quais mecanismos sociais levariam à sucessão de uma a outra etapa técnica. Na verdade, como acabamos de demonstrar, não se trata de sucessão de sistemas técnicos, mas sim de regimes de acumulação de capital. Cada um destes regimes, em seu desenrolar histórico e geográfico, produz técnicas que lhes são apropriadas. Lembrando a distinção de Ellul (1968), técnica e máquina não se confundem, em que pese a máquina, sob o capitalis mo seja o resultado de todo um procedimento técnico-científico. A técnica é o "saberfazer", a máquina é resultado material de tal "saber fazer".

Uma agenda de pesquisa a ser executada refere-se à necessidade de se articular o desenvolvimento técnico da sociedade capitalista com a sucessão de seus regimes de acumulação. Isto tanto é verdade, que se se observa as técnicas de exploração do trabalho, diferenciam-se a cada regime de acumulação. Veja por exemplo o taylorismo, fordismo e toyotismo. Isto vale também para o conjunto tecnológico tanto do aparato produtivo propriamente dito, quanto para o conjunto de técnicas e tecnologias presentes na sociedade. Este não é, entretanto, nosso objetivo aqui. Queremos tão-somente demonstrar que Milton Santos ao independentizar de certa forma os "sistema técnicos" não consegue compreender que estes estão subordinados, até o último parafuso, ao conjunto das relações sociais capitalistas e estas são historicamente determinadas e sucedem-se de acordo com os regimes de acumulação de capital.

Já temos elementos suficientes agora para concluirmos com nossa tese, ou seja, de que há em Milton Santos uma não-visão da luta de classes. Digo não-visão da luta de classes no sentido de que ele não explicita em sua argumentação a ação criadora e revolucionária do proletariado e demais classes exploradas e oprimidas da sociedade moderna. Isto não implica que ele não identifique que existam diferenças de classes ${ }^{5}$. O

\footnotetext{
${ }^{5} \mathrm{O}$ que ele denomina de atores hegemônicos e atores não-hegemônicos. Preferimos o uso da palavra classe social dado seu sentido político. Seria muito estranho, de nosso ponto de vista, dizer que existe uma consciência dos atores não-hegemônicos. Preferimos o termo, por exemplo, consciência de classe do proletariado, do campesinato, do lumpemproletariado etc. Além desta opção política, há também uma questão metodológica. Quando se fala em atores, hegemônicos e não-hegemônicos, coloca-se num
}

Ateliê Geográfico Goiânia-GO v. 6,n. $4 \quad$ Dez/2012 p.175-196 Página 190


que ele não consegue observar é que as classes exploradas tem um papel ativo tanto em colocar em crise os regimes de acumulação, quanto de construir uma nova sociedade, bem como interferem na determinação do aparato tecnológico ${ }^{6}$.

Utiliza os conceitos de racionalidade para expressar a lógica dos "atores hegemônicos" e contra-racionalidades para expressar a reação dos "atores nãohegemônicos". Para ele: "Esse meio técnico-científico é formado de objetos que incluem saber técnico e são o suporte do saber hegemônico, enquanto os outros espaços se tornam apenas os espaços do fazer" (Santos, 1997b, p. 2442). A distinção de classes gera, portanto, a distinção de posição dentro do meio técnico. Uns ordenam, outros obedecem. Até aí, nada de estranho.

Em seguida afirma:

$\mathrm{Na}$ medida em que os agentes locais da produção agrícola, rurais ou urbanos, tem um poder de controle limitado sobre o que é localmente produzido, o conhecimento das relações entre produção local e os aspectos mais globais do intercâmbio acelera essa produção política, aparecendo como um limite à racionalidade, uma vontade de contrariá-la ou o desejo de lhe sobrepor outros objetivos (Santos, 1997b, p. 245)

Ou seja, a situação de subordinado é em si mesma um limite à racionalidade. Será que a situação de explorado em si mesmo já é condição e cria de fato o desejo de "sobrepor outros objetivos"? Será que o fato de os agentes explorados (locais) simplesmente por serem explorados cria a possibilidade de saírem de sua situação? Continuemos expondo a tese do autor.

Segundo ele, paralelamente à racionalidade dominante, instalam-se as irracionalidades, as contra-racionalidades. Afirma:

\begin{abstract}
Essas contra-racionalidades se localizam, de um ponto de vista social, entre os pobres, os migrantes, os excluídos, as minorias: de um ponto de vista econômico, entre as atividades marginais, tradicional ou recentemente marginalizadas; e, de um ponto de vista geográfico, nas áreas menos modernas e mais "opacas", tornadas irracionais para usos hegemônicos. Todas essas situações se definem pela sua incapacidade de subordinação completa às
\end{abstract}

mesmo balaio gatos que são diferentes. Dentre os atores não-hegemônicos, por exemplo, estão o campesinato, o proletariado, o lumpemproletariado, funcionários subalternos das formas de regularização etc. Entre os atores hegemônicos estão a burguesia, a burocracia, a intelectualidade, os proprietários fundiários etc. Ou seja, é um equívoco utilizar um mesmo conceito para expressar classes sociais diferentes.

${ }^{6}$ Para uma discussão acerca da interferência das lutas de classes na determinação do aparato técnicotecnológico, notadamente do processo produtivo, cf. Marx (1984), Gorz (1980) e Romero (2005).

Ateliê Geográfico Goiânia-GO v. 6,n. $4 \quad$ Dez/2012 p.175-196 Página 191


racionalidades dominantes, já que não dispõem dos meios para ter acesso à modernidade material contemporânea. Essa experiência da escassez é a base de uma adaptação criadora à realidade existente (Santos, 1997b, p. 246).

Novamente aparece aqui como contra-racinalidade a própria condição de explorado e de subordinado. A condição de "pobre", de "migrante", de "minorias" de um ponto de vista social; de "atividades marginais", "tradicional", "recentemente marginalizadas" de um ponto de vista econômico; e "áreas menos modernas" e "mais opacas" de um ponto de vista geográfico seriam uma contra-racionalidade. Será mesmo? "Todas essas situações se definem pela sua incapacidade de subordinação completa às racionalidade dominantes (...)". Todas essas situações são, portanto, externas à produção capitalista. Todas essas situações seriam algo que o capital poderia evitar integrando-os aos seus circuitos de produção e consumo. "Essa experiência da escassez é a base de uma adaptação criadora à realidade existente". A miséria absoluta seria, portanto, a condição mais revolucionária do capitalismo. Quanto mais faminto for um indivíduo ou grupo de indivíduos mais potencialmente revolucionários eles seriam. Será que a história das lutas sociais confirma esta idéia?

E dá o xeque-mate:

O fato de que a produção limitada de racionalidade é associada a uma produção ampla de escassez conduz os atores que estão fora do círculo da racionalidade hegemônica à descoberta de sua exclusão e à busca de formas alternativas de racionalidade, indispensáveis à sua sobrevivência. A racionalidade dominante e cega acaba por produzir os seus próprios limites (Santos, 1997b, p. 247).

Novamente aparece a idéia de que estes "atores" são externos à racionalidade, ou seja, são aqueles que não conseguiram ou não foram subordinados à lógica da racionalidade dominante. $\mathrm{Na}$ verdade, eles são um produto direto desta racionalidade. Não são externos a ela, lhes pertencem de corpo e alma. Ou seja, toma como limite à racionalidade, algo que na verdade é determinado por esta, algo que vem de suas entranhas.

Dois elementos sustentam a argumentação de Milton Santos: a) a situação em si de pobreza, escassez etc. já é em si uma "contra-racionalidade"; b) os "atores nãohegemônicos" são externos à racionalidade dominante. O grande problema desta tese é que ela é totalmente falsa. Não existe no capitalismo contemporâneo nada que lhe seja 
externo. As teias da produção capitalista estendem-se na atualidade a todo o globo terrestre, subordinam todo o conjunto da natureza (ambiente), subordinam toda a existência humana (a produção de bens materiais, os valores, a mentalidade, o desejo, a consciência etc.). Ou seja, não existem os "excluídos". Todos são um produto genuíno do capital.

Deste primeiro erro deriva o segundo, que diz respeito ao primeiro ponto de sua argumentação. O que ele defende como contra-racionalidade é na verdade o produto e a permanência da exploração capitalista. Ele quer encontrar algo emancipador onde na verdade se localizam elementos de conservação. Ou seja, a fome como relação social não produz em si mesma sua capacidade de extinção, a pobreza em si mesma não produz a possibilidade de seu fim, as prisões em si mesmas não produzem as chamas da liberdade etc. Ou seja, falta em sua leitura, o elemento ativo das lutas de classes.

Em síntese, Milton Santos vê como emancipador algo que na verdade é uma derivação lógica e histórica da produção capitalista. A isto estou denominando a nãovisão da luta de classes em Milton Santos. A potencialidade criativa do proletariado e demais classes oprimidas é apagada em sua interpretação. Isto cria, do ponto de vista político, um entrave ao avanço das lutas sociais. As sucessivas crises nos regimes de acumulação são provocadas, como vimos, pela conjugação de dois processos: ascensão e radicalização das lutas de classes e pela natureza própria do capitalismo expressa por Marx na idéia de tendência declinante da taxa de lucro médio. Ou seja, a possibilidade de mudança não está na miséria em si, mas sim no que a situação de miséria pode criar em termos de ação criativa dos explorados. Aí entra na análise o contexto histórico, geográfico, o papel das ideologias, mentalidade, valores, sentimentos, a ação estatal etc. Trata-se de um processo complexo que envolve múltiplas determinações. E Milton Santos não consegue perceber todo este conjunto de processos.

Pode-se perceber isto também na visão de conflito, no que se refere às ações, defendida por Milton Santos:

Existiriam, pois, paralelamente essas três ordens: a ordem da forma técnica, a ordem da forma jurídica e a ordem do simbólico. O cotidiano se dá mediante essas três ordens. Mas se, por um lado, a ordem técnica e a ordem da norma impõem-se como dados, por outro lado, a força de transformação e mudança, a surpresa e a recusa ao passado, vêm do agir simbólico, onde $o$ que é força está na afetividade, nos modelos de significação $e$ representação. A importância do lugar na formação da consciência vem do fato de que essas formas do agir são inseparáveis, ainda que, em cada 


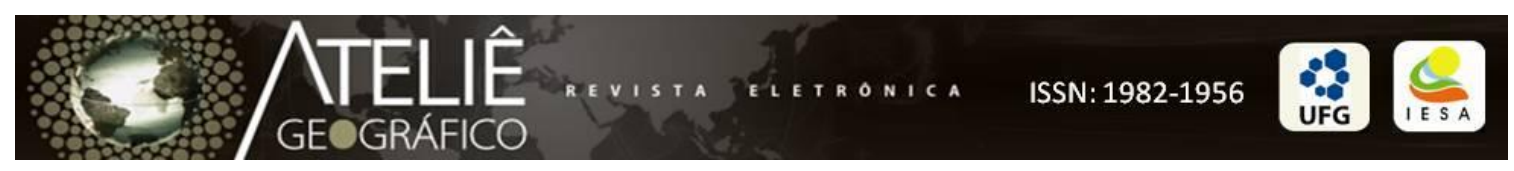

circunstância, sua importância relativa não seja a mesma (Santos, 1997b, p. 67. (grifos meus)

Apresenta um modelo de luta, de conflito, que, como qualquer modelo, carece de força explicativa da realidade. As ordens de ação se dariam em três níveis: técnica, jurídica, simbólica. Sendo a técnica e a jurídica, a ordem de ações vindas dos atores hegemônicos. A simbólica, pelo contrário, expressa a possibilidade de outra ordem de ações, vinda dos atores não-hegemônicos. São a negação da razão instrumental e técnica dos atores hegemônicos. Sua possibilidade emancipadora reside no reverso da medalha das ações técnica e jurídica. A ordem do simbólico caracteriza-se pelo afetivo, pela significação, pela representação. A linguagem do autor é por demais abstrata e expressa de modo muito limitado a matéria em discussão. Isto prejudica compreender o sentido verdadeiro de suas assertivas. Opõe um agir "racional": técnico e jurídico a um agir simbólico, aquele que encarnaria a possibilidade da mudança.

Não seria por acaso a possibilidade de mudança o resultado também de um agir racional executado pelas classes exploradas? O uso da palavra atores no lugar da palavra classes sociais permite um tipo de construção como este. As classes exploradas são pois agentes de mudança quando executam uma luta contra as classes e as condições que a oprimem. Isto não é uma forma de agir que se caracterize pelo afetivo, pelo simbólico etc., mas sim, uma luta motivada por questões concretas e quando adquire uma força revolucionária, ou seja, um potencial claro de mudança é produto de decisão racional, refletida, coletiva e não um mero ato afetivo. Vê-se com facilidade a limitação de se opor num modelo o racional versos o simbólico no que se refere às ações presentes na sociedade. Penso que é muito mais proveitoso discernir entre ações conservadoras e ações transformadoras. Ambas caracterizadas por um conjunto de elementos formais (regras) e valorativos, ações concretas, sentimentais etc.

Assim, para encerrar, quero destacar que a não-visão das lutas de classes nos processos de interpretação das relações sociais causa problemas tanto de ordem metodológica, mas principalmente de natureza política. Não considerar como sendo estruturante dos processos que se desenrolam na sociedade capitalista a luta de classes leva inevitavelmente a não compreender a lógica das lutas sociais. Foi este um dos grandes problemas de Milton Santos ao desenvolver o conceito de meio técnicocientífico-informacional. Deste problema central derivam os outros: visão descritivista

Ateliê Geográfico Goiânia-GO v. 6,n. 4 Dez/2012 p.175-196 Página 194


do desenvolvimento das etapas da sociedade capitalista; percepção contraditória da determinação da tecnologia pelas relações sociais; não-compreensão do papel ativo das classes exploradas e oprimidas nos processos de transformação social etc. Espero ter sido claro com relação a estes pontos.

\section{Uma última palavra}

Espero com este texto ter contribuído de alguma forma para a compreensão dos processos sociais que se desenvolvem na contemporaneidade. Criticar as ideologias é função de todo e qualquer indivíduo que queira dar seu quinhão de aportes às lutas sociais. Este opúsculo tem esta pretensão. Não se trata, deste modo, de competição acadêmica ou algo que o valha. Tentamos simplesmente reconhecer os méritos das contribuições de Milton Santos para a leitura geográfica da realidade. Sua discussão sobre os significados históricos e políticos do conceito de meio técnico-científicoinformacional é bastante elucidativa. Entretanto, como demonstramos, há lacunas em suas elaborações e foram estas lacunas que tentamos preencher, mesmo que tendo às vezes que inverter completamente as formulações do autor. Julgamos que inserir, de modo central no conceito de meio técnico-científico-informacional, a luta de classes é uma passo adiante nesta matéria. Este foi o eixo central de nossa argumentação.

\section{Referências Bibliográficas}

ELLUL, Jacques. A técnica e o desafio do século. Rio de Janeiro: Paz e Terra, 1968.

GORZ, André. O despotismo da fábrica e suas consequências. In: Crítica da divisão do trabalho. São Paulo: Martins Fontes, 1980.

JENSEN, Karl. A luta operária e os limites do "autonomismo". Revista Ruptura, Goiânia, ano 8, nº 07, p. 24-31, ago, 2001.

MARX, Karl. O capital: critica da economia política: o processo global da produção capitalista. Volume IV. T. 1. São Paulo: Nova Cultural, 1988.

O capital: critica da economia política: o processo global da produção capitalista. Volume I. T. 2. São Paulo: Nova Cultural, 1984. 
ROMERO, Daniel. Marx e a técnica: um estudo dos manuscritos de 1861-1863. São

Paulo: Expressão Popular, 2005.

SANTOS, Milton. Espaço e método. São Paulo: Nobel, 1997a.

A natureza do espaço. São Paulo: HUCITEC, 1997b.

Técnica, espaço, tempo: globalização e meio técnico-científico-

informacional. São Paulo: Hucitec, 1998.

VIANA, Nildo. A concepção dialética do conceito. In: A consciência da história: ensaios sobre o materialismo histórico-dialético. Rio de Janeiro: Achiamé, 2007.

Letras, 2009.

O capitalismo na Era da Acumulação Integral. Aparecida, SP. Idéias \&

Estado, Democracia e Cidadania: a dinâmica da política institucional no capitalismo. Rio de janeiro: Achiamé, 2003.

Recebido para publicação em outubro de 2011 Aprovado para publicação em dezembro de 2011 